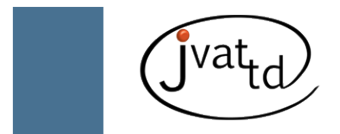

\title{
Organ tropism during the acute and chronic phases of Trypanosoma cruzi infection in BALB/c mice
}

Oliveira LRC (1), Picka MCM (1), Nicolete VC (1), Calvi SA (1), Marcondes-Machado J (1)

(1) Department of Tropical Diseases, Botucatu Medical School, São Paulo State University (UNESP - Univ Estadual Paulista), Botucatu, São Paulo State, Brazil.

\begin{abstract}
The aim of the present study was to investigate the presence of Trypanosoma cruzi in the heart, liver, lung, and kidneys, using hemoculture and PCR analysis, of mice infected with different parasite strains during the acute and chronic phases of infection. Parasitemia curves revealed strain-specific biological behaviors. For the $\mathrm{Y}$ and JLP strains, the acute phase of infection started at days six and ten post-infection, parasitemia peaked at days seven and 15 post-infection, the chronic phase started at days nine and 28 post-infection, and animals started dying at days 19 and 120 post-infection, respectively. When the two strains were compared, the JLP strain exhibited reduced and slower replication rates associated with a delayed peak of parasitism and reduced parasite burdens. However, parasites were detected in all studied organs using PCR analysis. The capacity of both strains to infect different organs likely influences disease pathogenesis.
\end{abstract}

Key words: Trypanosoma cruzi, PCR, hemoculture, organs, distribution.

\section{INTRODUCTION}

Chagas disease is a serious public health problem in Central and South America, where 18 million people are infected and $25 \%$ of the population is at risk for infection. It is estimated that 100,000 people die from the disease each year (1).

The causal agent of Chagas disease is Trypanosoma cruzi, an hematophagous protozoan of the Trypanosomatidae family (2). Genetic heterogeneity exists within T. cruzi, and various subpopulations or strains of T. cruzi exhibit distinct biological, biochemical, and immunological characteristics. According to their biological behavior, T. cruzi strains are classified as biodeme I, II, or III, which in turn correspond to specific zymodemes. Rapidly multiplying strains that result in high parasitemia during infection belong to biodeme I, while strains with relatively slow multiplication rates that exhibit irregular parasitemia peaks during infection belong to biodeme II. Lastly, slowly multiplying strains that exhibit late parasitemia peaks during infection belong to biodeme III. T. cruzi strains can also be classified according to their phylogenetic lineages, T. cruzi I: these strains are most often found in sylvatic transmission cycles, in which participate more than two hundred species of wild hosts and triatomine. T. cruzi circulates among wild mammals through insect vectors. The T. cruzi II strains are more common in the domestic transmission cycle (where triatomine bugs are found) and are best studied, they affect humans, and synanthropic animals. The infection began when humans moved to the wild ecotopes in rural houses, providing food and abundant shelter for vectors $(1,3,4)$.

Chagas disease has an acute phase in which 
the trypomastigote form of the parasite is abundant in the peripheral blood; in contrast, during the chronic phase, the amastigote form of the parasite is abundant in tissues. During the chronic phase, approximately $50 \%$ of infected individuals present with an indeterminate form of the disease, while the remaining individuals develop either the cardiac or digestive forms of the disease (5). Within the body, amastigotes perpetuate the infection and are found in the various tissues and cells associated with local inflammatory reactions. In general, all T. cruzi strains have demonstrated tropism for muscle and nerve tissues; however, parasites have also been found in the skin, spleen, kidneys, pancreas, liver, heart, brain, and lungs $(6,7)$.

The inflammatory response in the myocardium is generally more intense and diffuse and does not correlate with parasite numbers. In combination with edema, the intense mononuclear infiltrate, which is fundamental to Chagas disease pathogenesis, dissociates cardiac fibers and results in different levels of tissue destruction that leave the parasites clearly visible $(3,8-10)$. In mouse lungs, amastigotes are detected only in the muscular stratum of pulmonary blood vessels, with a localized inflammatory reaction (6). Information on renal involvement in T. cruzi infection is scarce, with little clarity regarding the infection risk for kidneys. Using monoclonal antibodies, Mortara et al. (7) found intracellular amastigotes undergoing division in the kidney. Studies using BALB/c mice infected with the $\mathrm{Y}$ strain of T. cruzi showed renal damage on the 6th day after infection caused by a transitory decrease in renal blood flow. In a similar ischemia model, occasional amastigote nests of $T$. cruzi were observed by microscope in the renal parenchyma on day 15 post-infection (11). The liver plays a fundamental role in the removal of circulating parasites. In a study of mice with chronic Chagas disease, Sardinha et al. (12) identified live trypomastigotes that had been phagocytosed by Kupffer cells 48 hours after intravenous inoculation, suggesting that the parasites were not immediately destroyed.

T. cruzi infection is detected using parasitological techniques, which are more sensitive during acute infection, and serological assays, which are more sensitive during chronic infection when parasitemia is low. Hemoculture, one of the parasitological methods, involves the addition of patient blood samples to an enriched medium, such as liver infusion tryptose (LIT) media, to encourage the multiplication of any parasites present. Molecular methods can also be utilized; one such method is polymerase chain reaction (PCR), which consists of the in vitro amplification of T. cruzi DNA fragments present in blood, serum, or tissue samples from infected patients. This technique is highly sensitive, detecting minute quantities of DNA from a single cell of the parasite (13).

Both host and parasite characteristics can influence the course of $T$. cruzi infection. Following the initial contact with host cells, parasites can disseminate to different organs and tissues, an important factor that likely determines the pathogenesis of the different clinical disease forms. Thus, the objective of this study was to investigate the presence of $T$. cruzi in the heart, liver, lungs, and kidneys of BALB/c mice infected with different parasite strains during the acute and chronic phases of infection using hemoculture and PCR analysis.

\section{MATERIALS AND METHODS}

\section{Animals}

Thirty isogenic male BALB/c mice aged between eight and 12 weeks were used in this study. The animals were bred and kept at the Tropical Diseases Research Laboratory Animal Center of the Botucatu Medical School, São Paulo State University (UNESP). At the time of experimentation, animals weighed approximately $30 \mathrm{~g}$. Housing conditions were kept between 25 and $27^{\circ} \mathrm{C}$, with a 12 hour/12 hour day/ night cycle. Animals were fed and watered ad libitum. The Research Ethics Committee of the Botucatu Medical School, UNESP, approved the experimental protocols.

\section{Parasites and Infection}

T. cruzi strain JLP, which was isolated from a patient with chronic Chagas disease treated at the FMUSP Heart Institute, and T. cruzi strain $\mathrm{Y}$ were both used in this study. The strains were kindly provided by Dr. Vicente Amato Neto from the USP Institute of Tropical Medicine. The strains were maintained at the Tropical Diseases Research Laboratory through weekly passages in $\mathrm{BALB} / \mathrm{c}$ mice. Animals used in this experiment were intraperitoneally infected with 
$100 \mu \mathrm{L}$ of blood containing trypomastigotes at a concentration of $1 \times 10^{5}$ trypomastigotes $/ \mathrm{mL}$. The required infection concentration was attained by counting parasites in a Neubauer chamber and adjusting the volume accordingly.

\section{Definition of the Acute and Chronic Infection Phases}

Starting on day one post-infection, $5 \mu \mathrm{L}$ samples of caudal blood from infected mice were examined by optical microscopy to determine the number of parasites using Brener's technique (14). This procedure was used to define the acute, high parasitemia phase of infection and the chronic, low parasitemia phase of infection for the two strains. These data were then used to determine the time points for organ removal. The following moments during infection were established: M1, 24 hours after infection $($ day +1$)$; $\mathrm{M} 2$, beginning of the acute phase; M3, maximum peak of parasitemia (acute phase); M4, moment of parasite burden decrease with maintenance of parasitemia (beginning of chronic phase); M5, final euthanasia time point as determined by the mortality curve of infected animals. Mouse survival was observed by daily inspection of cages. Deaths were noted, and survival percentages were calculated at the end of the study.

\section{Experimental Groups}

Mice were distributed into two groups of 15 animals each: G1 and G2. G1 mice were infected with the JLP strain, and G2 mice were infected with the Y strain. Infection was confirmed through parasite detection at the time of euthanasia; direct examination of blood samples $(5 \mu \mathrm{L})$ was performed according to Brener's technique (14). Euthanasia time points were determined using the parasitemia curves constructed for the JLP and $Y$ strains. Three animals from each group were euthanized at each moment. Euthanasia was performed using an excessive dose of anesthetic (Hypnol 3\%, Syntec, Brazil). The heart, liver, kidneys, and lungs were removed following euthanasia for culture and PCR analysis.

\section{Organ Cultures}

The strains were cultured in LIT medium that contained $2 \mathrm{~g} \mathrm{Na}_{2} \mathrm{HPO}_{4}$ (Nuclear, Brazil), $1 \mathrm{~g} \mathrm{NaCl}$ (Synth, Brazil), 0,1 g KCl (Dinâmica, Brazil), 0,75 g liver infusion (Difco-Diagnostic Systems/BD Diagnostics, USA), 0,5 g dextrose
(Oxoid, England), 1,25 g tryptose (Vetec, Brazil), $2.2 \%$ bovine hemoglobin (BBL), $11 \%$ fetal bovine serum (Nutricell, Brazil), and $20 \mathrm{mg}$ gentamycin (NeoQuímica, Brazil). The final mixture was distributed into sterile tubes and kept in an incubator at $27^{\circ} \mathrm{C}$ until use. Each LIT medium preparation was tested with $T$. cruzi strain $\mathrm{Y}$ to verify quality. Organs (heart, spleen, liver, and kidneys) were aseptically removed under laminar flow conditions, washed in PBS, and macerated in $2 \mathrm{~mL}$ of LIT medium. Each organ macerate was then placed into tubes containing $5 \mathrm{~mL}$ of LIT medium. The tubes were kept between $28^{\circ} \mathrm{C}$ and $30^{\circ} \mathrm{C}$ in an incubator and were analyzed using the hemoculture method. After 15 days of incubation, $5 \mu \mathrm{L}$ of medium was placed between a slide and cover slip for analysis. Each sample was analyzed every 14 days until a maximum of 180 days. The presence of trypanosomes indicated a positive result.

\section{PCR Analysis of Organ Cultures}

After 180 days, the LIT medium cultures were washed two to three times in PBS ( $\mathrm{pH}$ 7.2), and the sediment was stored at $-80^{\circ} \mathrm{C}$ until use. Total DNA extraction was performed using 300 $\mu \mathrm{L}$ of culture samples according to protocol 2 of the GFXTM Genomic Blood DNA Purification ${ }^{\oplus}$ kit (Amersham Biosciences, USA). Primers S35 (5-AAATAATGTACGGGGGAGATGCATGA $\left.-3^{\prime}\right)$ (Invitrogen), described in Sturm et al. (15), were used. These primers amplified a $330 \mathrm{bp}$ product specific to the $\mathrm{kDNA}$ minicircle region of $T$. cruzi. Each reaction mixture consisted of PCR buffer (50 mM KCL, $200 \mathrm{mM}$ Tris$\mathrm{HCL}$ (Invitrogen, Canada), $50 \mathrm{mM} \mathrm{MgCl}_{2}$ (Invitrogen), $100 \mathrm{mM}$ deoxynucleotide solution (Invitrogen), Platinum ${ }^{\circledR}$ Taq DNA polymerase (Invitrogen), $10 \mathrm{pmol}$ of each oligonucleotide (Invitrogen), ultrapure water, and the sample to be tested. Amplification conditions in the thermocycler were as follows: 1 cycle of $96^{\circ} \mathrm{C}$ for two minutes; 30 cycles of $94^{\circ} \mathrm{C}, 60^{\circ} \mathrm{C}$, and $72^{\circ} \mathrm{C}$ for one minute each; and one cycle of $72^{\circ} \mathrm{C}$ for ten minutes. Aliquots of the amplification products were mixed with bromophenol blue solution (USB, USA) and submitted to horizontal electrophoresis in $1.0 \%$ agarose gels stained with GelRed $^{\circledast}$ (Amersham Bioscience). A proprietary 100-bp DNA Ladder (Invitrogen) was used as a molecular weight marker. The positive controls were amplified products from T. cruzi strains $\mathrm{Y}$ 
and JLP kept by the Tropical Diseases Research Laboratory. Bands were visualized using an ultraviolet transilluminator.

\section{Statistical Analysis}

The number of T. cruzi-positive samples of heart, liver, lung, and kidneys were analyzed using an adjusted generalized linear model with Poisson distribution to test the effects of strain, method, and time. Interactions between the strain and method were also assessed. Comparisons between organs used the same method, which was adjusted considering the strain, method, time, and organ as main effects. Interactions between organ, strain, and method were also assessed. All analyses used a significance level of $5 \%$. Comparisons between the number of positive organs and the stages of infection were made using the Kruskal-Wallis test.

\section{RESULTS}

\section{Parasitemia Curves}

Parasitemia curves for both strains were constructed to determine euthanasia time points. For strain Y, which is considered an acute strain, the acute phase was determined to start on day six post-infection, peak parasitemia occurred on day seven post-infection, the chronic phase began on day 9 post-infection, and mortality occurred starting on day 19 post-infection (Figure 1). For the JLP strain, the acute phase started on day 10 post-infection, peak parasitemia occurred on day 15 post-infection, the chronic phase began on day 28 post-infection, and mortality occurred starting on day 120 post-infection (Figure 2 and data not shown). JLP parasites exhibited decreased and slower replication rates, with a delayed parasitemia peak and reduced parasite burdens compared with the Y strain.

\section{Parasite Detection in Different Organs Using Hemoculture and PCR Analysis}

Hemoculture of animals infected with T. cruzi strain $Y$ revealed parasites in the heart of one animal at M5 (a significant difference compared with other moments). In contrast, PCR analysis revealed parasite DNA in the heart at M2 (two animals), M3 (three animals), M4 (three animals), and M5 (three animals), demonstrating a significant difference compared with M1 (Table 1). A significant difference was also observed between methods (Table 2). Although JLP strain parasites were not detected in the heart by hemoculture, T. cruzi DNA was detected using PCR analysis at M3 (three animals), M4 (three animals), and M5 (two animals) (Table 3), demonstrating a significant difference compared with M1 and M2 (Table2). There was no significant difference between T. cruzi strains in the heart by hemoculture and PCR analysis (Table 2).

Hemoculture of lung samples from strain Y-infected animals detected parasites in two animals at M3, in one animal at M4, and in three animals at M5. A significant difference was observed when M1 and M2 were compared with M5. Lung samples tested positive for $T$. cruzi DNA by PCR analysis at all moments,

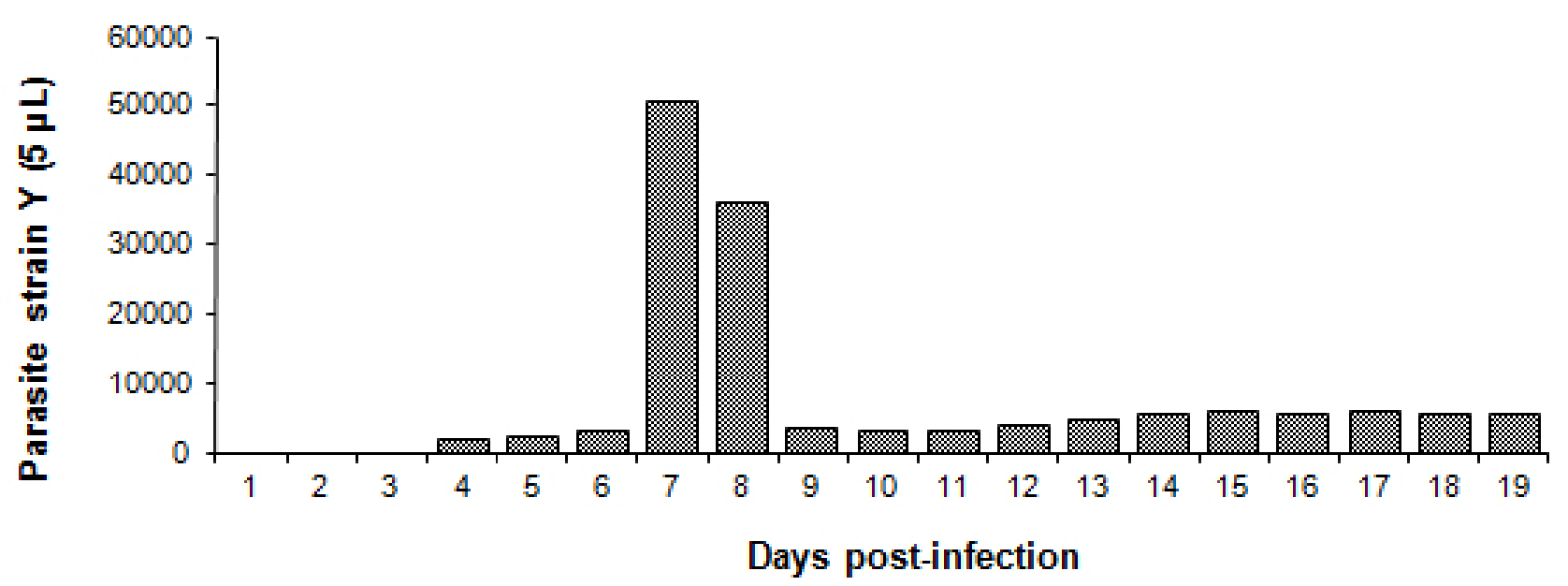

Figure 1. Parasite load in BALB/c mice after infection with $1 \times 10^{5}$ trypomastigotes $/ \mathrm{mL}$ of $T$. cruzi strain Y. Data represent the mean number of parasites (ten mice per group). 


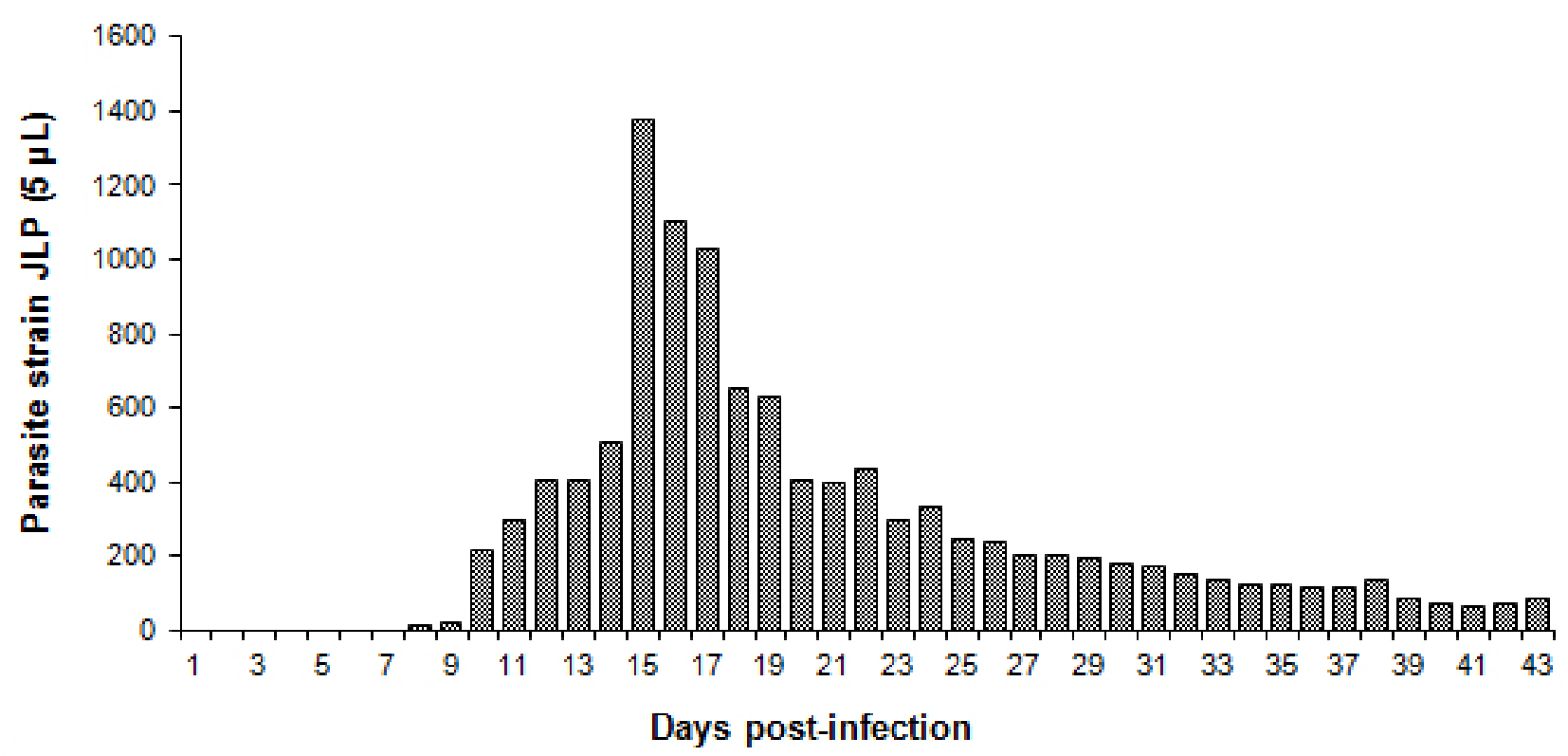

Figure 2. Parasite load in BALB/c mice after infection with $1 \times 10^{5}$ trypomastigotes $/ \mathrm{mL}$ of $T$. cruzi strain JLP. Data represent mean number of parasites (ten mice per group).

with one animal testing positive at $\mathrm{M} 1$ and all animals testing positive at M2, M3, M4, and M5. Significant differences were observed between M1 and all other moments (Table 1). There was no significant difference between the methods for strain Y (Table 4). In the JLP strain-infected animals, hemoculture detected parasites in the lung at M1 (two animals), M2 (one animal), M4 (one animal), and M5 (one animal). The difference between moments M1 and M3 was significant. PCR analysis of lungs from JLP strain-infected animals revealed positive results for all animals at all moments tested (Table 3). Again, there was no significant difference between the methods (hemoculture and PCR) (Table 4). There was also no significant difference between the strains (JLP e Y) (Table 4).

In the liver and kidneys, no parasites were detected using hemoculture in any animal at any moment for both strains. For strain Y, PCR analysis of liver samples detected positive results in two animals at M2, two animals at M3, three animals at M4, and two animals at M5. For the kidneys, PCR analysis detected positive results in two animals at M2, and three animals each at M3, M4, and M5. Significant differences were observed between M1 and M4 in the liver. Significant differences were also observed between M1 and M3 and between M4 and M5 in the kidneys (Table 1). Liver and kidney samples from JLP-infected

Table 1. Number of animals that tested positive by hemoculture or PCR analysis in different organs of mice infected with T. cruzi strain $Y$

\begin{tabular}{c|c|c|c|c|c}
\hline \multirow{2}{*}{} & \multicolumn{5}{|c}{ Strain $\mathrm{Y}$ (Hemoculture/PCR) } \\
\cline { 2 - 6 } & M1 & M2 & M3 & M4 & M5 \\
\hline Heart & $0 / 0$ & $0 / 2$ & $0 / 3^{\mathrm{b}}$ & $0 / 3^{\mathrm{b}}$ & ${ }^{\mathrm{a}} 1 / 3^{\mathrm{b}}$ \\
\hline Lung & $0 / 1^{\mathrm{c}}$ & $0 / 3$ & $2 / 3$ & $1 / 3$ & ${ }^{\mathrm{d}} 3 / 3$ \\
\hline Liver & $0 / 0$ & $0 / 2$ & $0 / 2$ & $0 / 3^{\mathrm{e}}$ & $0 / 2$ \\
\hline Kidney & $0 / 0$ & $0 / 2$ & $0 / 3^{\mathrm{f}}$ & $0 / 3^{\mathrm{f}}$ & $0 / 3^{\mathrm{f}}$ \\
\hline
\end{tabular}

Significant differences between moments in hemoculture and PCR in the different organs are given as $p<0.05$. a: versus M1, M2, M3, and M4; b: versus M1; c: versus. M2, M3, M4, and M5; d: versus M1 and M2; e: versus M1; and f: versus M1 ( $n=3$ mice in each time point) 
Table 2. Comparison between strains and methods (hemoculture versus PCR) in heart samples from BALB/c mice infected with T. cruzi strain Y or strain JLP

\begin{tabular}{c|c|c}
\hline & \multicolumn{2}{|c}{ Strains } \\
\hline Methods & Y & JLP \\
\hline Hemoculture & $0.12 \pm 0.32 \mathrm{~A} \mathrm{a}$ & $0.08 \pm 0.28 \mathrm{~A} \mathrm{a}$ \\
\hline PCR & $0.73 \pm 0.45 \mathrm{~B} \mathrm{~b}$ & $0.40 \pm 0.49 \mathrm{~B} \mathrm{~b}$ \\
\hline
\end{tabular}

Horizontally, equivalent uppercase letters indicate non-significant results $(p>0.05)$.

Vertically, equivalent lowercase letters indicate non-significant results $(p>0.05)$

Table 3. Number of animals whose organs tested positive, by hemoculture or PCR analysis, following infection with T. cruzi strain JLP

\begin{tabular}{c|c|c|c|c|c}
\hline & \multicolumn{5}{|c}{ Strain JLP (Hemoculture/PCR) } \\
\hline & M1 & M2 & M3 & M4 & M5 \\
\hline Heart & $0 / 0$ & $0 / 0$ & $0 / 3^{\mathrm{a}}$ & $0 / 3^{\mathrm{a}}$ & $0 / 2$ \\
\hline Lung & b2/3 & $1 / 3$ & $0 / 3$ & $1 / 3$ & $1 / 3$ \\
\hline Liver & $0 / 0$ & $0 / 0$ & $0 / 2$ & $0 / 0$ & $0 / 0$ \\
\hline Kidney & $0 / 0$ & $0 / 0$ & $0 / 1$ & $0 / 0$ & $0 / 0$ \\
\hline
\end{tabular}

Significant differences between moments in hemoculture and PCR in the different organs are given as $p<0.05$. a: versus $M 1$ and $M 2$; and b: versus M3 ( $n=3$ mice in each time point).

Table 4. Comparison between strains and methods (hemoculture versus PCR analysis) in lung samples from BALB/c mice infected with T. cruzi

\begin{tabular}{c|c|c}
\hline & \multicolumn{2}{|c}{ Strains } \\
\hline Methods & JLP & Y \\
\hline Hemoculture & $0.33 \pm 0.49 \mathrm{~A} \mathrm{a}$ & $0.40 \pm 0.51 \mathrm{~A} \mathrm{~b}$ \\
\hline PCR & $0.87 \pm 0.35 \mathrm{~B} \mathrm{a}$ & $0.87 \pm 0.35 \mathrm{~B} \mathrm{~b}$ \\
\hline
\end{tabular}

Horizontally, equivalent uppercase letters indicate non-significant results ( $p>0.05)$;

Vertically, equivalent lowercase letters indicate non-significant results $(p>0.05)$.

mice tested positive only at M3. At this infection moment, liver samples from two animals tested positive and kidney samples from one animal tested positive (Table 3 ). The statistical model could not be applied to either organ due to the large number of negative samples.

In general, the organ analyses for hemoculture showed significant differences between the heart and the lungs, the lungs and the liver, and the lungs and the kidneys. PCR analyses revealed significant differences between the liver and the lungs and the lungs and the kidneys. Comparing methods, there were significant differences between detection methods in the heart and the lungs (Table 5). The PCR results for the detection of T. cruzi DNA in heart, liver, lung, and kidney samples are shown in Figure 3.

\section{DISCUSSION}

Although Chagas disease known to exhibit variable clinical courses, the fundamental phenomenon of this variability is still not well understood. Several studies have shown that the different pathological manifestations in the clinical forms of the disease can be linked to differences 
Table 5. Comparison between organs and methods (hemoculture and PCR analysis) for BALB/C mice infected with T. cruzi

\begin{tabular}{c|c|c|c|c}
\hline & \multicolumn{4}{|c}{ Organs } \\
\hline Methods & Heart & Liver & Lung & Kidney \\
\hline Hemoculture & $0.03 \pm 0.18 \mathrm{~A} \mathrm{a}$ & $0.00 \mathrm{~A}$ & $0.37 \pm 0.49 \mathrm{~B} \mathrm{a}$ & $0.00 \mathrm{~A}$ \\
\hline PCR & $0.63 \pm 0.45 \mathrm{~A} \mathrm{~B} \mathrm{~b}$ & $0.40 \pm 0.50 \mathrm{~A}$ & $0.87 \pm 0.35 \mathrm{~B} \mathrm{~b}$ & $0.37 \pm 0.49 \mathrm{~A}$ \\
\hline
\end{tabular}

Horizontally, equivalent uppercase letters indicate non-significant results ( $p>0.05)$.

Vertically, equivalent lowercase letters indicate non-significant results $(p>0.05)$.

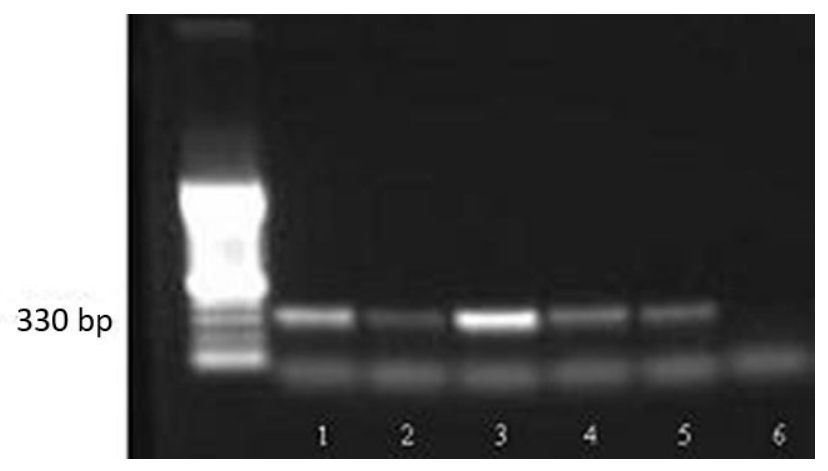

Figure 3. Polymerase chain reaction $(P C R)$ analysis for the detection of T. cruzi DNA. Sample 1, heart; sample 2, liver; sample 3, lung; sample 4, kidney; sample 5, positive control; sample 6, negative control.

in host immune responses, such as the capacity to control parasitemia, induce an inflammatory response, and induce autoimmunity (16-18). Another factor that could determine the clinical disease course is the pathogenicity of T. cruzi. This parasite is a heterogenic species composed of various subpopulations that circulate between various domestic and wild vertebrate and invertebrate hosts (19). According to Andrade et al. (20), T. cruzi strains are complex multiclonal populations that have different genetic and biological characteristics and exhibit different behaviors in vertebrate hosts.

In this study, we assessed parasite distribution in different organs (the heart, liver, lung, and kidneys) during the acute and chronic phases of infection for two different T. cruzi strains to determine whether a particular strain displayed a tropism for a particular organ. A murine model was used to enable the temporal analysis to assess the behavior of different strains in these organs during acute and chronic infection, which is not possible in humans $(6,21)$. Initially, a parasitemia curve was constructed for each strain. Mice infected with strain $\mathrm{Y}$ parasites exhibited an early peak of parasitemia at day seven postinfection with large numbers of parasites being detected. These findings are consistent with the previously established profile for the $\mathrm{Y}$ strain that classified it as an acute strain belonging to biodeme I, characterized by rapid multiplication and high parasitemia during infection $(1,3,4)$. Mice infected with strain JLP parasites exhibited a delayed peak of parasitemia, with decreased parasite burdens and much longer animal survival times. These results indicate that strain JLP is not as acute as strain $\mathrm{Y}$ and could belong to biodeme III, which is characterized by slow multiplication and delayed parasitemia peaks $(1,3,4)$. In a study using the same experimental infection model (unpublished data), these strains were also classified accordingly to phylogenetic lineage as domestic transmission cycle strains. Based on the genetic background of T. cruzi strains, Zingales et al. (22) divided TCI and TCII groups into six different units (I-VI) according to their DTU. DTUs are defined as "sets of stocks that are genetically more related to each other than to any other stock and that are identifiable by common genetic, molecular, or immunological markers" (22). According to Zingales et al. (22), the Y strain of the present study should be classified as a TCII strain. Because the two strains were both classified as belonging to the domestic transmission cycle, we suggest that the JLP strain can also be classified as a TCII strain (22). The results of the present study agree with other studies that indicate one type of strain is predominant within the same geographical area (20).

Macrophages are the main cells involved in $T$. cruzi recognition after infection, both in humans and animals. Actively phagocytosed parasites 
can either be destroyed or multiply in the phagocyte cytoplasm. This process is followed by parasite dissemination in vertebrate organisms, with intracellular multiplication in different tissues (20). Several strains of T. cruzi exhibit histotropism, where parasite multiplication occurs predominantly in one tissue but is not excluded in other tissues. During the acute phase of infection, parasites are present in different organs; however, during the chronic phase of infection, parasites destroy specific organs, such as the heart (23). The results of our study show that by using PCR analysis, parasites can be detected in the liver, lung, kidneys, and heart. Parasite presence was homogenous in all organs for both strains, and strains did not exhibit any differences in organ preference as expected for histotropism. This observation is corroborated by Andrade et al. (20), who demonstrated that within a specific geographic area a predominant biodeme or zymodeme may lead to specific clinical signs. Although the JLP strain was isolated from a patient with chronic Chagas disease, it disseminated into different organs even during the chronic infection phase, suggesting that despite the low numbers of parasites, this strain is probably not found during a typical chronic infection. While different infection phases were detected in the heart, these differences were not strain-related. These results agree with other studies that have demonstrated that while T. cruzi parasites can invade different tissues, they preferentially invade the heart and digestive tissues (24-27). Other authors have verified that during the course of the infection, the highest concentration of parasite DNA, and presumably of the parasites themselves, is found in the myocardium, highlighting the importance of this tissue in confirming a Chagas disease diagnosis $(24,28,29)$.

Our study also found parasites in the lungs using both hemoculture and PCR analysis, highlighting the importance of this organ. Parasites were detected in the lungs during different infection phases without any differences between the strains. These results agree with a study by Melnikov et al. (6), who demonstrated the presence of amastigotes from various strains of Mexican T. cruzi in lung structures, a finding that conflicted with earlier studies using strains from South America. Melnikov et al. (6) also detected innumerable amastigote nests in lung tissue and muscular stratum of all conducting branches of large bronchi and bronchioles. These parasite agglomerates were accompanied by mononuclear inflammatory infiltrate; consequently, the airway walls exhibited thickening, edema, and a significant reduction in lumen size. Although the parasites were not observed in lung respiratory zones (terminal bronchioles and small alveoli), serious pathological alterations were observed in the alveoli walls, including hypercellularity, mononuclear and lymphocytic infiltrates, and extensive alveolar hemorrhage. In addition, Bittencourt et al. (30) found parasites in the lungs and amniotic fluid of newborns.

Descriptions of renal involvement in Chagas disease are scarce in the literature. Strain Y parasites were detected, using PCR analysis, in the kidneys at all infection moments, except the first day after infection. In contrast, strain JLP parasites were only detectable in the kidney at the peak of infection. In a case report of a patient after renal transplant, amastigote nests were detected in the renal parenchyma after immunosuppression (31). In a study using acute, experimental T. cruzi infection, Lenzi et al. (32) found parasites in the renal parenchyma, vessels, and capsule. In our study, PCR-positive renal structures could not be specified because whole organ culture was performed. These results require further study because the kidney is an important infection route, especially in transplant cases and endemic areas. In experimental infections, T. cruzi promotes systemic alterations, and alterations in kidney function may promote cardiovascular dysfunction progression and the genesis of cardiac insufficiency (11).

The results in the liver were similar to those found in the kidney. Strain Y parasites were detected in the liver at all infection moments except day one post-infection, while strain JLP parasites were only detected in the liver using PCR analysis at the peak of infection. These data are consistent with other studies in which amastigote nests and intense inflammatory infiltrates were found in histological sections of the liver $(11,33$, 34). Macrophages, Kupffer cells, and hepatocytes can be colonized by $T$. cruzi. Together with the abundant presence of phagocytic immune cells in the liver, this colonization enables the liver to play an important role in blood trypomastigote clearance.

In our study, PCR analysis detected T. cruzi in a greater number of organs that we examined, 
even during the chronic phase of infection. These results also agree with those of other authors who used this technique to detect T. cruzi in human and animal blood; further, these authors have also reported that PCR analysis is more sensitive than hemoculture and other methods normally used (35). This finding demonstrates that the increased sensitivity highlights the importance of including PCR analysis in study protocols to determine the infectivity tension and clarify the inconclusive results for diagnosis of Chagas disease. $(4,23,35$, 36).

Our results show that although the strains used in this study have the same phylogenetics, they exhibited different biological characteristics as demonstrated by their parasitemia curves; however, they also have similar parasite distribution profiles in the different organs studied during the acute and chronic phases of infection. These results suggest that the strains could still have been in the acute phase during the period evaluated, highlighting the need for a longerterm study to further investigate the chronic phase of infection. Our results also support the hypothesis that the capacity of both strains to infect different organs likely influences disease pathogenesis. Further studies are now being focused on gaining a better understanding of the host/parasite relationship, and how it influences different T. cruzi strains to infect specific organs.

\section{COPYRIGHT}

(c) CEVAP 2012

\section{SUBMISSION STATUS}

Received: May 23, 2011.

Accepted: October 3, 2011.

Abstract published online: October 6, 2011.

Full paper published online: February 28, 2012.

\section{CONFLICTS OF INTEREST}

The authors declare no conflicts of interest.

\section{ETHICS COMMITTEE APPROVAL}

The present study was approved by the Research Ethics Committee of Botucatu Medical School (protocol number 706/2008).

\section{CORRESPONDENCE TO}

Larissa Ragozo Cardoso De Oliveira,
Departamento de Doenças Tropicais e
Diagnóstico por Imagem, Faculdade de Medicina

de Botucatu, UNESP, Distrito de Rubião Jr, s/n, Botucatu, SP, 18618-000, Brasil. Phone: +551438116372 or +55143811 6212. Email: larissaragozo@yahoo.com.br.

\section{REFERENCES}

1. Sturm NR, Teixeira ARL, Nascimento RJ. Evolution and pathology in Chagas disease: a review. Mem Inst Oswaldo Cruz. 2006;101(5):463-91.

2. MachadoEM,DiasFB,DiotaiutiL, RomanhaAJ,Bezerra M. First report on the occurrence of Trypanosoma rangeli Tejera, 1920 in the state of Ceará, Brazil, in naturally infected triatomine Rhodnius nasutus Stal, 1859 ( Hemiptera, Reduviidae, Triatominae). Mem Inst Oswaldo Cruz. 2007;102(5):645-5.

3. Devera R, Illarramendi X, Montoya-Araújo R, Pirmez C, Fernandes O, Coura JR. Biodemas de cepas do Trypanosoma cruzi isoladas de humanos de três áreas endêmicas de Minas Gerais. Rev Soc Bras Med Trop. 2002;35(4):323-30.

4. Bértoli M, Andó MH, De OrnelasToledo MJ, De Araújo SM, Gomes ML. Infectivity for mice of Trypanosoma cruzi I and II strains isolated from different hosts. Parasitol Rev. 2006;99(1):7-13.

5. Pompillio MA, Dorval ME, Cunha RV, Britto C, BorgesPereira J. Epidemiological, clinical and parasitological aspects of Chagas disease in Mato Grosso do Sul State. Rev Soc Bras Med Trop. 2005;38(6):473-8.

6. Melnikov VG, Velasco FF, Espinoza Gómez F, Rodríguez FG, Dobrovinskaya OR. Pathologic changes in lungs caused by Mexican isolates of Trypanosoma cruzi in the acute phase of infection in mice. Am J Trop Med Hyg. 2005;73(2):301-6.

7. Mortara RA, da Silva S, Patrício FR, Higuchi ML, Lopes ER, Gabbai AA, et al. Imaging Trypanosoma cruzi within tissues from chagasic patients using confocal microscopy with monoclonal antibodies. Parasitol Res. 1999;85(10):800-8.

8. Pinto PL, Takami R, Nunes EV, Guilherme CS, Oliveira OC Jr, Gama-Rodrigues J, et al. Life cycle of Trypanosoma cruzi (Y strain) in mice. Rev Hosp Clin Fac Med São Paulo. 1999;54(5):141-6.

9. Oliveira KM, Souza NB Jr, Mata, FR, Sabóia-Morais SM, Aversi-Ferreira TA, Mata JR. Alterações teciduais agudas induzidas em ratos Wistar por Trypanosoma cruzi. Rev Eletr Farm. 2007;4(1):86-94.

10. Guarner J, Bartlett J, Zaki SR, Colley DG, Grijalva MJ, Powell MR. Mouse model for Chagas disease: immunohistochemical distribution of different stages of Trypanosoma cruzi in tissues throughout infection. Am J Trop Med Hyg. 2001;65(2):152-8.

11. de Oliveira GM, da Silva TM, Batista WS, Franco M, Schor N. Acute Trypanosoma cruzi experimental infection induced renal ischemic/reperfusion lesion in mice. Parasitol Res. 2009;106(1):111-20.

12. Sardinha LR, Mosca T, Elias RM, do Nascimento RS, Gonçalves LA, Bucci DZ, et al. The liver plays a major role in clearance and destruction of blood trypomastigotes in Trypanosoma cruzi chronically 
infected mice. PLoS Negl Trop Dis. 2010;4(1):e578

13. Neves J. Diagnóstico e tratamento de doenças infecciosas e parasitárias. Rio de Janeiro: Guanabara Koogan; 2005.

14. Brener Z. Therapeutic activity and criterion of cure on mice experimentally infected with Trypanosoma cruzi. Rev Inst Med Trop São Paulo. 1962;4:396-8.

15. Sturm NR, Degrave W, Morel C, Simpson L. Sensitive detection and schizodeme classification of Trypanosoma cruzi cells by amplification of kinetoplast minicircle DNA sequences: use in diagnosis of Chagas' disease. Mol Biochem Parasitol. 1989;33(3):205-14.

16. Marin-Neto JA, Cunha-Neto E, Maciel BC, Simões MV. Pathogenesis of chronic Chagas heart disease. Circulation. 2007;115(9):1109-23.

17. Arce-Fonseca M, Ballinas-Verdugo MA, Reyes PA, Aranda-Fraustro A, Monteón VM. Autoantibodies to human heart conduction system in Chagas' disease. Vector Borne Zoonotic Dis. 2005;5(3):233-6.

18. Manoel-Caetano F da S, Silva AE. Implications of genetic variability of Trypanosoma cruzi for the pathogenesis of Chagas disease. Cad Saúde Pública. 2007;23(10):2263-74.

19. da Silva MA, Nai GA, Rosa JA. Caracterização biológica e molecular de quatro cepas de Trypanosoma cruzi isoladas de pacientes na fase crônica, forma cardíaca da doença de Chagas. Rev Patol Trop. 2006;35(3):21326.

20. Andrade SG, Magalhães JB. Biodemes and zymodemes of Trypanosoma cruzi strains:correlations with clinical data and experimental pathology. Rev Soc Bras Med Trop. 1997;30(1):27-35.

21. Beck JA, Lloyd S, Hafezparast M, Lennon-Pierce M, Eppig JT, Festing FW, et al. Genealogies of inbred strains. Nature Genetics. 2000;24(1):23-5.

22. Zingales B, Andrade SG,. Briones MRS, Campbell DA, Chiari E, et al. A new consensus for Trypanosoma cruzi intraspecific nomenclature: second revision meeting recommends TcI to TcVI. Mem Inst Oswaldo Cruz. 2009;104(7):1051-4.

23. Vera-Cruz JM, Magallón-Gastelum E, Grijalva G, Rincón AR, Ramos-García C, Armendáriz-Borunda J. Molecular diagnosis of Chagas' disease and use of an animal model to study parasite tropism. Parasitol Res. 2003;89(6):480-6.

24. Hagar JM, Rahimtoola SH. Chagas' heart disease in the United States. N Engl J Med. 1991;325(11):763-8.
25. Vago AR, Macedo AM, Adad SJ, Reis DD, CorrêaOliveira R. PCR detection of Trypanosoma cruzi DNA in oesophageal tissues of patients with chronic digestive Chagas' disease. Lancet. 1996;348(9031):891-2.

26. Cummings KL, Tarleton RL. Rapid quantitation of Trypanosoma cruzi in host tissue by real-time PCR. Mol Biochem Parasitol. 2003;129(1):53-9.

27. Andrade LO, Machado CR, Chiari E, Pena SD, Macedo AM. Differential tissue distribution of diverse clones of Trypanosoma cruzi in infected mice. Mol Biochem Parasitol. 1999;100(2):163-72.

28. Zhang L, Tarleton RL. Parasite persistence correlates with disease severity and localization in chronic Chagas' disease. J Infect Dis. 1999;180(2):480-6.

29. Jones EM, Colley DG, Tostes S, Lopes ER, VnencakJones CL, McCurley TL. Amplification of a Trypanosoma cruzi DNA sequence from inflammatory lesions in human chagasic cardiomyopathy. Am J Trop Med Hyg. 1993;48(3):348-57.

30. Bittencourt AL, Rodrigues de Freitas LA, Galvão de Araujo MO, Jácomo K. Pneumonitis in congenital Chagas' disease. A study of ten cases. Am J Trop Med Hyg. 1981;30(1):38-42.

31. Carvalho MF, de Franco MF, Soares VA. Amastigotas forms of Trypanosoma cruzi detected in a renal allograft. Rev Inst Med Trop São Paulo. 1997;39(4):2236.

32. Lenzi H, Oliveira D, Lima M, Gattass CR. Trypanosoma cruzi: paninfectivity of CL strain during murine acute infection. Exp Parasitol. 1996;84:16(1)27.

33. Ronco MT, Francés DE, Ingaramo PI, Quiroga AD, Alvarez ML, Pisani GB, et al. Tumor necrosis factor alpha induced by Trypanosoma cruzi infection mediates inflammation and cell death in the liver of infected mice. Cytokine. 2010;49(1):64-72.

34. Camandaroba E, Thé TS, Pessina DH, Andrade SG. Trypanosoma cruzi: clones isolated from the Colombian strain, reproduce the parental strain characteristics, with ubiquitous histotropism. Int J Exp Path. 2006;87(3):209-17.

35. Kirchhoff LV, Votava JR, Ochs DE, Moser DR. Comparison of PCR and microscopic methods for detecting Trypanosoma cruzi. J Clin Microbiol. 1996;34(5):1171-5.

36. Picka MC, Meira DA, de Carvalho TB, Peresi E, Marcondes-Machado J. Definition of a diagnostic routine in individuals with inconclusive serology for Chagas disease. Braz J Infect Dis. 2007;11(2):226-33. 